\section{Vietnam Journal of Agricultural Sciences}

\title{
Application of the Internet of Things Technology (lot) in Designing an Automatic Water Quality Monitoring System for Aquaculture Ponds
}

\author{
Nguyen Quang Huy ${ }^{1}$, Vu Thi Thu Giang ${ }^{2}$, Le Vu Quan ${ }^{1}$ \& Ho The \\ Vo Cuong ${ }^{1}$
}

${ }^{1}$ Faculty of Engineering, Vietnam National University of Agriculture, Hanoi 131000 Vietnam

${ }^{2}$ Faculty of Information Technology, Vietnam National University of Agriculture, Hanoi 131000, Vietnam

\begin{abstract}
The current paper aims to apply the Internet of Things technology (IoT) in designing an automatic system for measuring and monitoring important parameters of aquaculture ponds such as temperature, $\mathrm{pH}$, and dissolved oxygen (DO). The system includes the Arduino Nano main microcontroller (the device that transmits and pushes data to the Raspberry Pi 3 Web server), the DS18B20 temperature sensor module, the $\mathrm{pH}$ sensor module V1.1, and the DO Sensor SKU SEN0237. The system is capable of continuously measuring the above parameters of aquaculture ponds. The measurement results are stored and transmitted wirelessly to smart devices such as computers and mobile phones. Farmers can continuously monitor water quality parameters of aquaculture ponds $(\mathrm{pH}, \mathrm{DO}$, temperature) through these smart devices. In addition, a warning message will be sent to the farmer's phone when the DO index of the aquaculture pond falls below the prescribed level. The results of the test evaluation also show the high accuracy of the system when compared with the sample measuring device. All relative errors are satisfied less than the limit value of $5 \%$.
\end{abstract}

\section{Keywords}

IoT, Arduino Nano Micro, Raspberry, sensor, pond monitoring

\section{Introduction}

Vietnam is a country with a dense system of rivers and long seaways, which is very convenient for developing fishing and aquaculture activities. According to data from the Vietnam Association of Seafood Exporters and Producers (2020), Vietnam's seafood production has maintained continuous growth over the past 17 years with an average increase of $9.07 \%$ per year. With the 
Vietnamese government's policy of promoting the development of the aquaculture, aquaculture activities have made strong development steps, the output from aquaculture activities has continuously increased over the years with an average of $12.77 \%$ increase per year, making a significant contribution to the growth of the country's total fishery output. According to a report by the General Department of Fisheries (2020), the value of fishery production in 2018 reached about VND $228,139.8$ billion, an increase of $7.7 \%$ as compared to 2017. The total output reached about 7.74 million tons, an increase of $7.2 \%$, of which fishing output reached 3.59 million tons, up $6.0 \%$, aquaculture reached 4.15 million tons, up $8.3 \%$, respectively.

Water quality in aquaculture ponds plays a crucial role in the growth and development of aquatic animals. Indicators that directly influence water quality in aquaculture ponds are DO concentration, temperature, $\mathrm{pH}, \mathrm{NH}_{3}$, Nitrite, $\mathrm{H}_{2} \mathrm{~S}$, alkalinity, salinity, mineral concentration, nitrate concentration, phosphorus concentration, bacterial density, and algae density, etc. All of these indicators must be within the threshold limits. As long as one of the above indicators exceeds the threshold limits, aquatic animals will be affected. For example, low DO in the water will lead to difficulty in breathing for aquatic organisms which may threaten their lives. Therefore, it is imperative to control all water quality indicators and have timely treatments to ensure they are within the threshold limits.

Among the above water quality indicators, there are some fast-changing indicators (continuously changing during the day) such as $\mathrm{DO}$, pond temperature, and $\mathrm{pH}$. These indicators need to be tracked and monitored all the time of the day. The remaining indicators, due to the low speed of change, can be monitored by test kits (KIT) or hand-held meters to reduce the investment cost for the monitoring system. Table 1 presents the limit of DO thresholds for some aquatic animals.

Recently, in Vietnam, the indicators of water quality of aquaculture ponds are mainly measured by hand-held meters as shown in Figure 1. These methods are not very effective since they must use manpower and can only be conducted manually a few times a day.

Therefore, the water quality parameters of the pond are not monitored continuously and may have brought inaccurate information.

Table 1. Threshold limits of DO of some aquatic animals (Vietnam Fisheries Society, 2018)

\begin{tabular}{ccc}
\hline Aquatic animal & $\begin{array}{c}\text { Critical limit of dissolved oxygen } \\
\left(\mathrm{mg} \mathrm{L}^{-1}\right)\end{array}$ & Dead zone $\left(\mathrm{mg} \mathrm{L}^{-1}\right)$ \\
\hline Coldwater fish & $5.0-6.0$ & $2.5-3.5$ \\
Warmwater fish & $4.0-5.0$ & $1.0-2.0$ \\
Shrimp & $3.0-4.0$ & $0.5-1.0$ \\
\hline
\end{tabular}
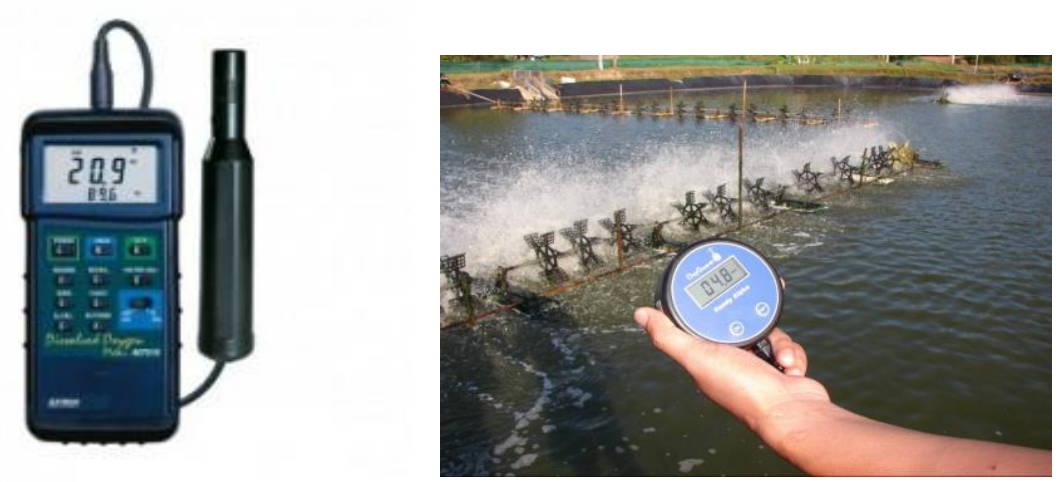

Figure 1. Some types of equipment for measuring DO in aquaculture ponds (Baonghean, 2020) 
Currently, the strong development of science and technology, especially the Internet of Things (IoT) and computer science, has led to the introduction of wireless measuring devices and sensor networks (Wireless sensor networks). IoT is a highly promising technology that is offering many innovative solutions to modernize the agriculture sector. Throughout the world, IoT and wireless technologies have been studied and applied in many different fields of agriculture such as farms and growers, fisheries, animal husbandry, and agribusiness supply chains. Existing research in this field has usually focused on measurement and monitoring of production environment parameters (Akhmetov \& Aitimov, 2015; Ran, 2014), precision agriculture (Lin, 2015), improving product quality (Athanasios \& Charalampos, 2010), and building a data management system forensuring food safety (Liu, 2015).

In Vietnam, the application of IoT technology in agricultural production has been initially researched and sporadically conducted. Binh \& Tri (2016) presented the simulation of measuring environment temperature in ponds using Matlab programming language. In their work, they build a virtual pond combining DS18B20 temperature sensor with Arduino microcontroller circuit and MATLAB software, and then create a tool to collect, store, and retrieve temperature data in a $3 \mathrm{D}$ environment of the virtual pond. In the study by Duy et al. (2015), the authors have initially applied sensors and controllers to monitor the parameters of the pond environment; however, the results are limited in monitoring some parameters such as temperature, $\mathrm{pH}$, and light intensity. The very important DO concentration was missing in their work. Moreover, the results have not been recorded and there have been no timely warnings to farmers when pond water quality indicators fall below threshold limits.

The above limitations motivated us to conduct our study. The aim of our work was to apply Internet of Things in measuring important indicators of the pond environment automatically and continuously. More specifically, in our system, $\mathrm{DO}, \mathrm{pH}$, and pond temperature are stored and transmitted wirelessly to smart devices (smartphones) or computers. Moreover, the system is also able to send warning messages to farmers immediately when the water quality indicators of the ponds are below the threshold limits.

\section{Materials and Methods}

\section{Overall structure of the system}

The ovarall structure of the automatic measurement and monitoring system of the parameters in aquaculture ponds is illustrated in Figure 2.

The indicators of the aquaculture ponds such as temperature, $\mathrm{pH}$, and $\mathrm{DO}$ are measured by sensors and then converted into voltage signals that are sent to the Arduino Nano central microcontroller. The microcontroller processes signals according to the installation algorithm, the data is then transferred to the Raspberry Pi3 block where the data is processed and pushed to the Web server. Users can use computers or smartphones with a network connection to track and monitor the parameters of aquaculture ponds, such as temperature, $\mathrm{pH}$, and $\mathrm{DO}$ concentration, through the ThingSpeak interface. Besides, when the DO level in the pond falls below the threshold limit, the system will send a warning message to the farmer's phone via a SIM 900 A module and turn on the aerator to timely supply additional DO to the pond.

Materials to design an automatic system of measuring and monitoring parameters in aquaculture ponds

Sensors used to measure parameters in aquaculture ponds

\section{DS18B20 temperature sensor}

To measure water temperature in aquaculture ponds, we used the DS18B20 sensor as shown in Figure 3. This is a MAXIM high resolution (12bit) temperature sensor, capable of Water resistant, with stainless compact design. The construction consists of a transducer immersed in water and an output consisting of 3 pins directly connected to the central control board.

\section{Specifications}


Power input: 3.0 to $5.5 \mathrm{~V}$

Usable temperature range: -55 to $125^{\circ} \mathrm{C}(-67$ to $+257^{\circ} \mathrm{F}$ )

Accuracy: $\pm 0.5^{\circ} \mathrm{C}$ accuracy from -10 to $+85^{\circ} \mathrm{C}$

Selectable resolution: $9-12$ bits

Query time: less than $750 \mathrm{~ms}$

Diameter of the tube: $6 \mathrm{~mm}$

Communication: 1-Wire interface- requires only one digital pin

Output: 3 wires - Red connects to $3-5 \mathrm{~V}$, Black connects to ground, and Yellow is for data
pH sensor

To measure the $\mathrm{pH}$ level of the water in the ponds, we used the $\mathrm{pH}$ sensor module V1.1 of Gizmo Mechatronix central as presented in Figure 4. The main construction of the sensor consists of a $\mathrm{pH}$ probe and a signal conditioning board which gives an output that is proportional to the $\mathrm{pH}$ value and can be interfaced directly with any Micro-controller.

\section{Specifications}

Power Input: 5VDC

Working Current: 5 to $10 \mathrm{~mA}$

Power Consumption: $0.5 \mathrm{~W}$

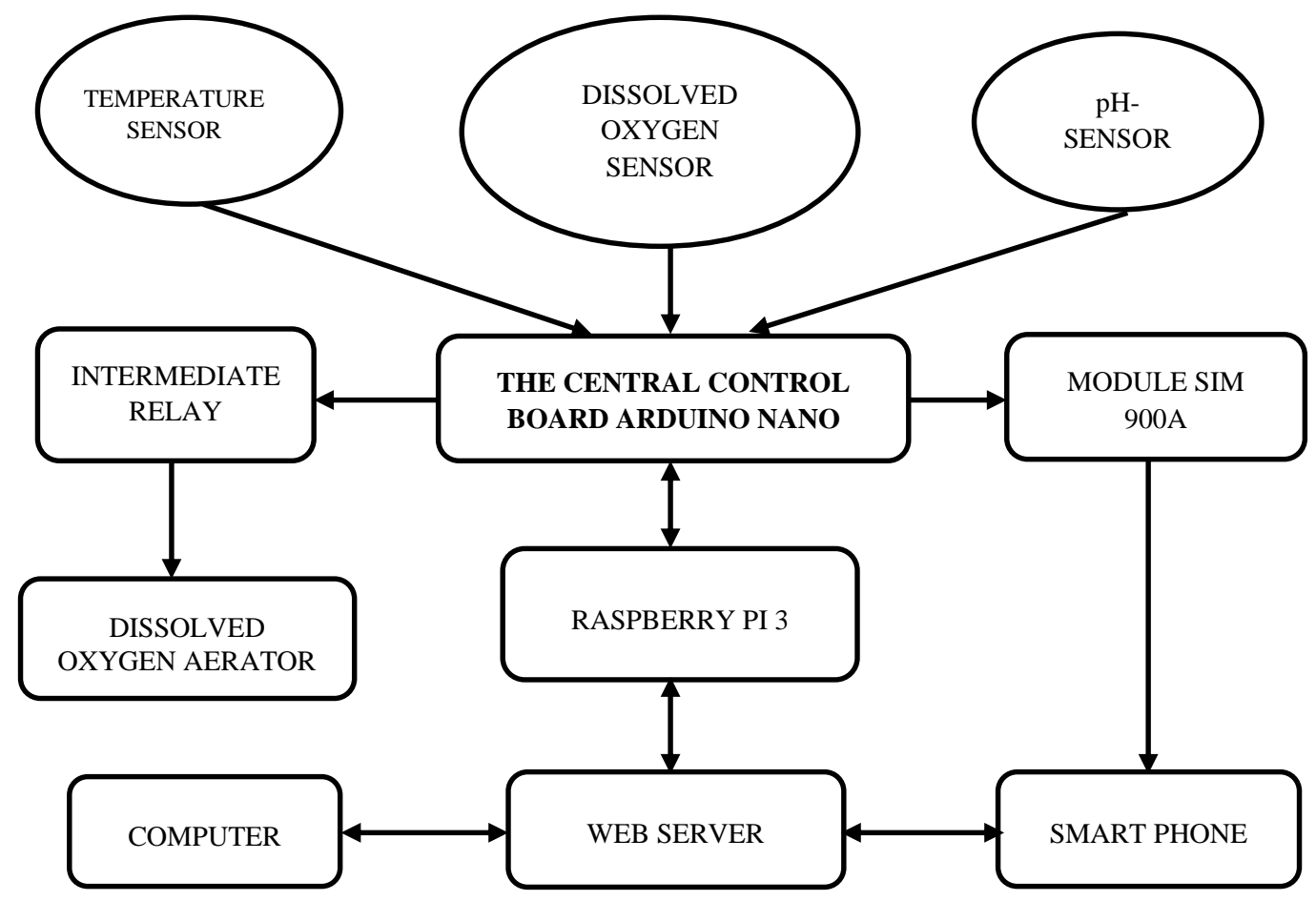

Figure 2. Structure diagram of the automatic system of measuring and monitoring parameters in aquaculture ponds

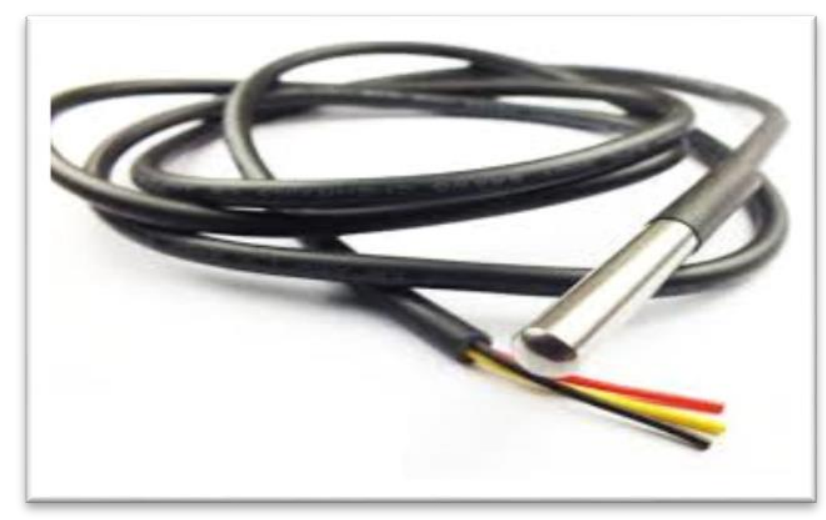

Figure 3. The DS18B20 temperature sensor (Getblocky, 2020) 
Response time: $5 \mathrm{~s}$

Detection Concentration Range: 0 to 14

Output: Analog

PCB Dimensions: 42 x 32mm

Working Temperature: -10 to $+50^{\circ} \mathrm{C}$.

Dissolved Oxygen (DO) sensor

The DO indicator in water plays a vital role in the development of aquatic animals. To measure this indicator, we used DO sensor module SKU SEN0237 developed by DFRobot as shown in Figure 5.

There are two main components of this sensor. The first one is a galvanic probe, no need for polarization time, and stays available at any time. The filling solution and membrane cap are replaceable, meaning low maintenance costs. The DO measuring range is $0-20 \mathrm{mg} \mathrm{L}^{-1}$, the response time is $90 \mathrm{~s}$, the working pressure range is 0-50Psi, and the connecting cable length is $2 \mathrm{~m}$. The second one is a $42 \times 32 \mathrm{~mm}$ signal converter board which is plug and play and has good compatibility. It can be easily integrated into any control or detecting system, the operating voltage is $3.3-5 \mathrm{~V}$, an the output signal is $0-3 \mathrm{~V}$.

\section{Central control board}

The central control board receives data from the sensors, implements control algorithms, and communicates with modules such as Raspberry and sim module. In our work, we use the Arduino Nano board. It is a small, complete, and breadboard-friendly board based on the microcontroller ATmega328P (Arduino Nano 3.x). It offers similar connectivity and specifications to the Arduino Uno Rev3 and works with a Mini-B USB cable instead of a

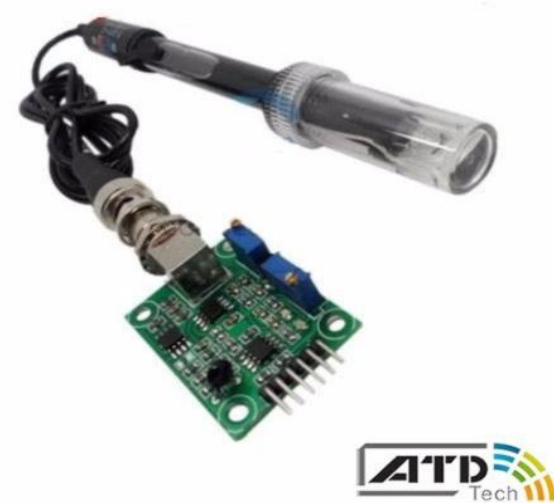

Figure 4. The pH sensor (Bo-cam-bien-do-do-ph-6060476, 2020)

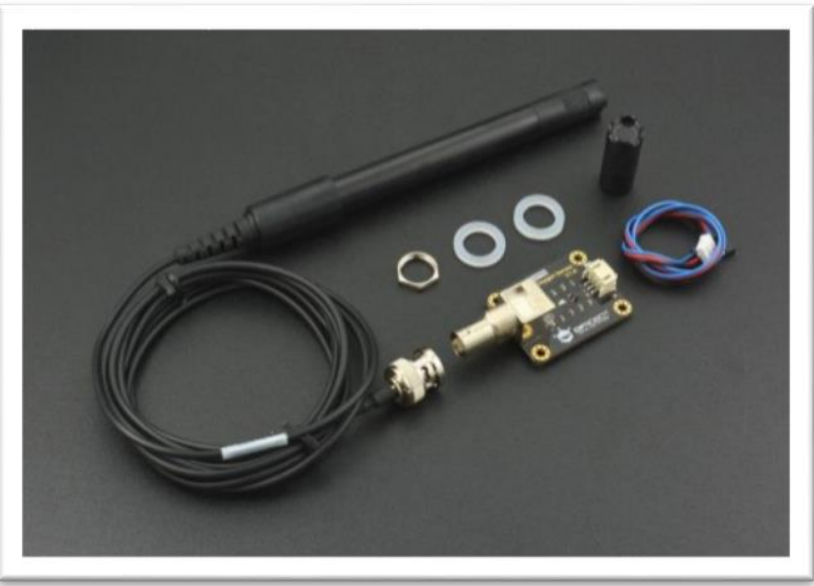

Figure 5. The Dissolved Oxygen (DO) sensor (mlab, 2020) 
standard one. Arduino Nano uses the $\mathrm{CH} 340$ chip to convert from USB to UART instead of using ATmega16U2 chip to simulate COM port as on Arduino Uno or Arduino Mega. Thus, the product costs are reduced while the main features and functions of the other boards are kept and the communication and programming of an Arduino Nano board can be performed easily.

\section{Specifications}

Microcontroller: ATmega328P

Communication chip: CH340 USB-Serial

Operating Voltage: $5 \mathrm{~V}$

Digital I/O Pins: 22 (6 of which are PWM)

Analog IN Pins: 8

DC Current per I/O Pins: 40mA (I/O Pins)

SRAM: $2 \mathrm{~KB}$

EEPROM: $1 \mathrm{~KB}$

Clock Speed: $16 \mathrm{MHz}$

\section{Raspberry Pi 3 Model B+ module}

The data of temperature, $\mathrm{pH}$, and $\mathrm{DO}$ were processed according to the programming algorithm at the central control board and then sent to the Raspberry Pi $3 \mathrm{~B}^{+}$module. Here the data continued to be processed and sent to the cloud where it was stored in either a private or a public channel, from which they would be stored and observed via computers and smartphones using the ThingSpeak platform.
The Raspberry Pi 3 Model $\mathrm{B}^{+}$, as in Figure $\mathbf{6}$, is the latest product in the Raspberry Pi 3 range, boasting a 64-bit quad-core processor running at $1.4 \mathrm{GHz}$, dual-band $2.4 \mathrm{GHz}$ and $5 \mathrm{GHz}$ wireless LAN, Bluetooth 4.2/BLE, faster Ethernet, and PoE capability via a separate PoE HAT.

\section{SIM 900 A module}

The process of sending a warning message to the farmer when the DO level in the pond fell below the threshold limits was carried out via SIM 900A module. It has basic features like a cell phone including calling, sending SMS, and accessing GPRS. Due to its high stability, simplicity of use, and 5VDC standard operating voltage. Figure 7 illustrates Sim 900 A module with the diagram of pins connected to the Arduino Nano central board.

\section{Dissolved Oxygen aerator}

To provide DO for a $0.45-\mathrm{m}^{3}$ tank, we used the Mini Pump with 5-12V MB385, the capacity of $12 \mathrm{~W}$, the flow of 4-5 L/Minute. This pump was controlled via an intermediate relay.

\section{Methods}

Algorithm flowchart of the automatic control system for measuring and monitoring aquaculture pond parameters

The Algorithm flowchart of the system of automatically measuring and monitoring the

\section{Raspberry Pi3 B+}

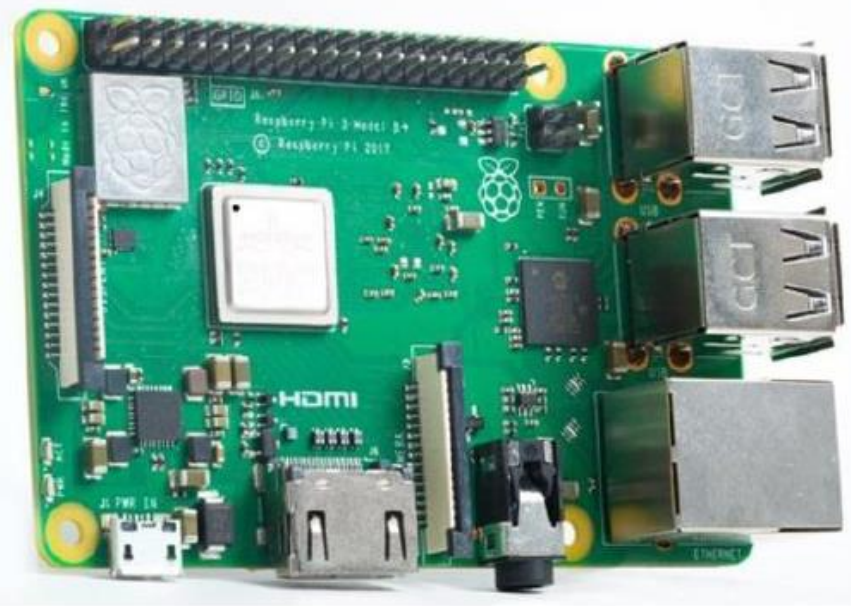

Figure 6. Module Raspberry Pi 3 B $^{+}$(Raspberrypi, 2020). 
parameters of aquaculture ponds is presented in Figure 8. The water quality indicators of the ponds, including temperature, $\mathrm{pH}$, and $\mathrm{DO}$ levels, were measured by the sensors, and then sent to the processor by the Arduino Nano controller chip. Here, we set the DO threshold limits at $2.0 \mathrm{mg} \mathrm{L}^{-1}$, if the DO level of the pond fell below $2.0 \mathrm{mg} \mathrm{L}^{-1}$, it would turn on the oxygen aerator to provide in-time with the amount of DO for the pond, and through the SIM 900A module, a warning message would be immediately sent to the farmer's phone. The temperature, $\mathrm{pH}$, and DO data were stored and pushed to the Cloud via the Raspberry Pi module. Farmers could use Thingspeak software installed on phones or computers to track and monitor these indicators continuously.

\section{Results and Discussion}

\section{Measurement results of temperature, $\mathrm{pH}$, and DO concentration}

To show the effectiveness of our system, we compared our measurement results and reference samples by the following standard machines:

- The water temperature meter: DYS HDT-10 type made by EMIN, Korea. It measurres temperature range from $-50^{\circ} \mathrm{C}$ to $+300^{\circ} \mathrm{C}$ with $\pm 1^{\circ} \mathrm{C}$ accuracy. This temperature meter meets the EC No. E8 040853916001 quality certification.

- The DO meter: DO Hanna HI9142 type made by Hanna Romania. The meter provides a full range $\mathrm{DO}$ readings from 0 to $19.9 \mathrm{mg} \mathrm{L}^{-1}$ with $\pm 1.5 \%$ accuracy.

- The pH meter: HI8314 type made by Hanna. It provides a full range of $\mathrm{pH}$ measurement from 0 to 14 with $\pm 0.01 \mathrm{pH}$ accuracy.

The results are presented in Tables $\mathbf{2 , 3}$, and 4. To achieve these results, we operated the system and conducted measurements 5 times per hour. The system can perform the measurement of parameters, viz. temperature, $\mathrm{pH}$, and $\mathrm{DO}$ of the ponds, continuously in a long time.

Tracking and monitoring parameters in aquaculture ponds via computer or Smartphone

By using the open-source ThingSpeak data transfer platform, we were able to track and monitor the parameters in aquaculture ponds including temperature, $\mathrm{pH}$, and $\mathrm{DO}$ indicators through computers or Smartphones. The users need a smart device (either smartphone or computer) that is connected to the internet. Then, one can access the ThingSpeak website and use the previously registered account and password to track the parameters of aquaculture ponds. During the process, if the DO level in the pond falls below the threshold level, the system will send a warning message to the farmer and turn on the aerator to provide oxygen to the pond. Figures 9 and 10 below illustrate the process of tracking and monitoring parameters on a computer and sending warning messages to farmers. To receive the warning messages, the

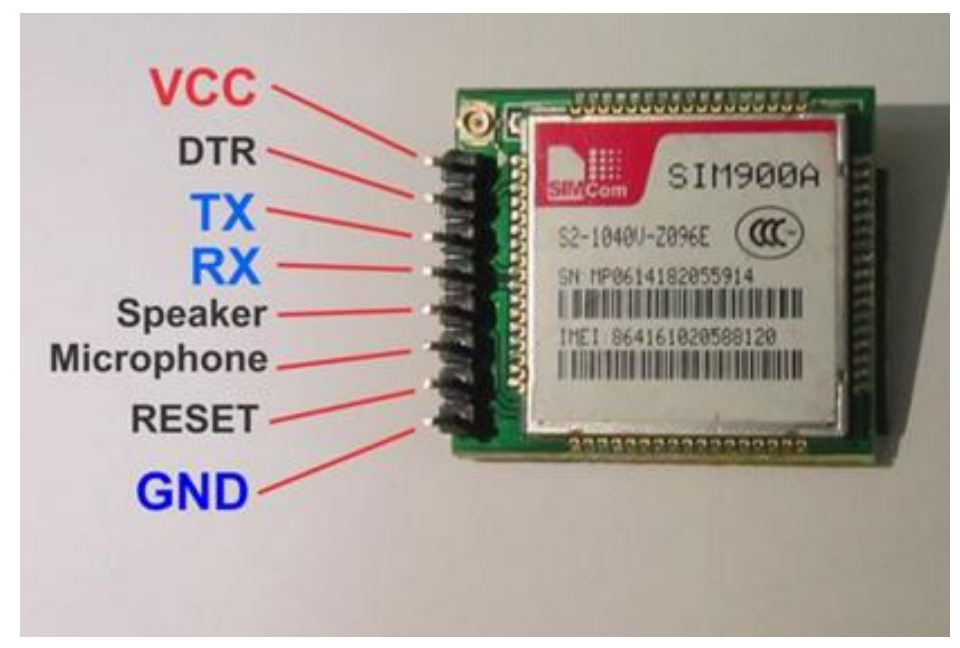

Figure 7. SIM 900 A module module (Arduino, 2020) 


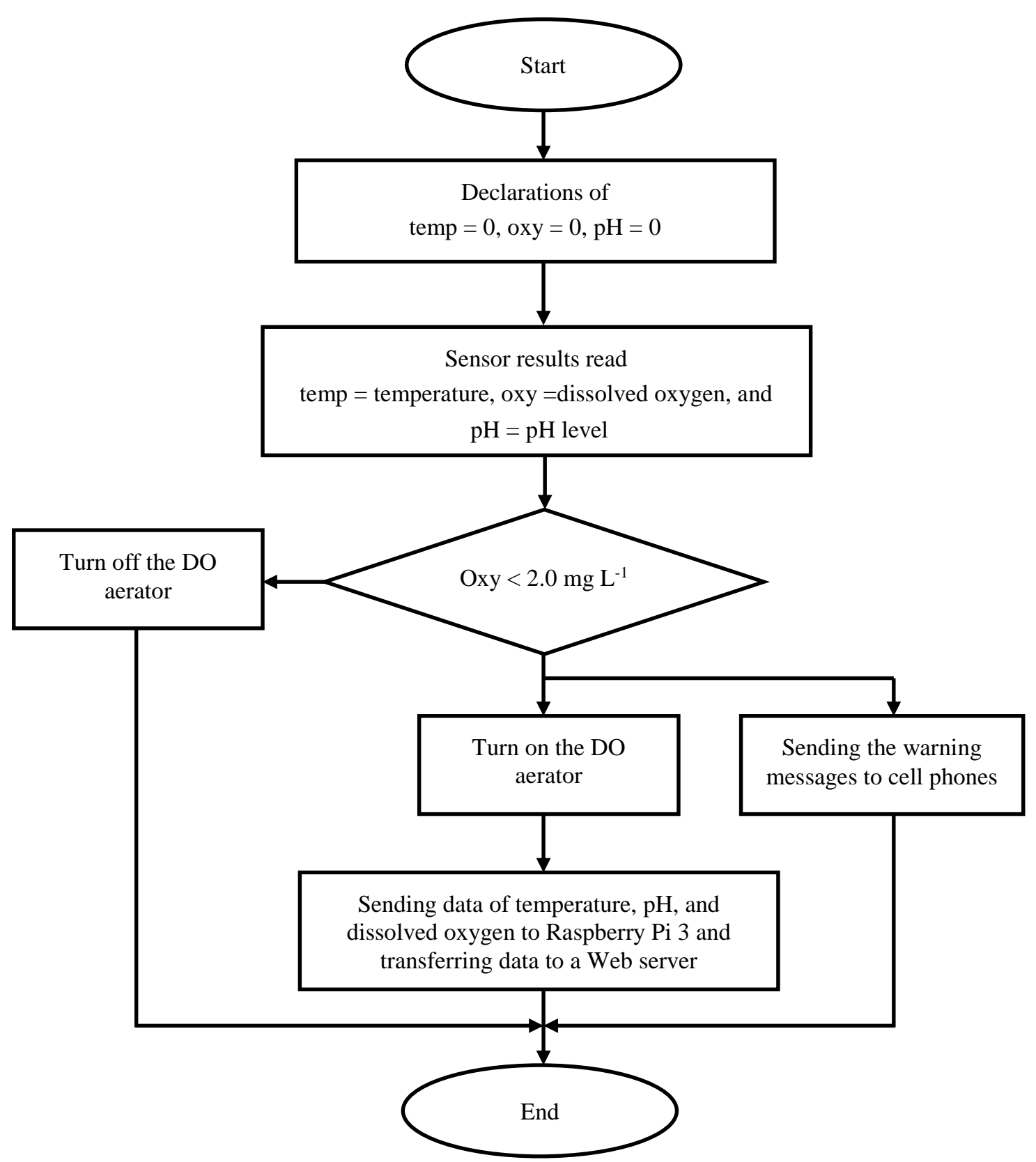

Figure 8. The Algorithm flowchart of the automatic system for measuring and monitoring parameters in aquaculture ponds

phone number of the user needs to be added into the coding for SIM 900 A Module. Then, the user needs to maintain monthly payments to keep the SIM 900 A active.

It can be seen that the system operated according to the requirements. The temperature, $\mathrm{pH}$, and DO indicators of the ponds were continuously measured, stored, and transmitted to the network. The maximum relative error of the result when compared to the sample measuring devices was $3.57 \%$, which was still lower than the limit value of $5 \%$. The measurement of DO was quite accurate with the maximum relative error of $2.88 \%$.

From the discussions above, we can see that by using this sytem, the users could actively track and monitor the parameters of the aquaculture ponds such as temperature, $\mathrm{pH}$, and $\mathrm{DO}$ concentration through smartphones or computers with internet access. All these parameters were stored in the system, and when the important index of DO in the pond fell below the specified level, there would be a warning message sent to the farmer so that a method could be applied to 
increase the DO level. In this case, the dissolved aerator machine would be turned on to timely provide DO to the pond. This is the main advantage of our system in comparison with the works of Duy et al. (2015) or Binh \& Tri (2016).

\section{Conclusions}

In this work, we presented the design of an automatic system for measuring and monitoring water quality indicators of aquaculture ponds, including temperature, $\mathrm{pH}$, and $\mathrm{DO}$. The test results showed that the system achieved accuracy in measuring temperature, $\mathrm{pH}$, and $\mathrm{DO}$, and was reliable and easy to use. The autonomic system is an important application of IoT technology in the field of aquaculture. It not only helps to reduce the time and effort of the farmers significantly but also helps to improve aquaculture's productivity. In the near future, more research is needed to develop the system to measure more water quality parameters such as turbidity, ammonia $\left(\mathrm{NH}_{3}\right)$, and hydrogen sulfide $(\mathrm{H} 2 \mathrm{~S})$ and to employ solar energy for the operation of the system.

\section{Acknowledgements}

This work was supported by the ARES Programwith Vietnam National University of Agriculture [grant number T2019-09-24VB].

Table 2. Comparison of temperature results

\begin{tabular}{|c|c|c|c|}
\hline Measurement times & $\begin{array}{l}\text { Results by the system } \\
\qquad\left({ }^{\circ} \mathrm{C}\right)\end{array}$ & $\begin{array}{l}\text { Results by the standard machines } \\
\qquad\left({ }^{\circ} \mathrm{C}\right)\end{array}$ & $\begin{array}{c}\text { Relative Error } \\
\text { (\%) }\end{array}$ \\
\hline 1 & 15.6 & 15.9 & 1.88 \\
\hline 2 & 17.8 & 18.3 & 2.73 \\
\hline 3 & 20.8 & 21.4 & 2.8 \\
\hline 4 & 22.2 & 22.9 & 3.05 \\
\hline 5 & 29.7 & 30.8 & 3.57 \\
\hline
\end{tabular}

Table 3. Comparison of $\mathrm{pH}$ level results

\begin{tabular}{cccc}
\hline Measurement times & $\begin{array}{c}\text { Results by the system } \\
\left(\mathrm{mol} \mathrm{L}^{-1}\right)\end{array}$ & $\begin{array}{c}\text { Results by the standard machines } \\
\left(\mathrm{mol} \mathrm{L}^{-1}\right)\end{array}$ \\
\hline 1 & 7.8 & 7.8 & 0 \\
2 & 7.9 & 7.8 \\
3 & 7.8 & 7.8 & 0 \\
4 & 7.7 & 7.8 & 7.28 \\
5 & 8.0 & 7.82 & 2.56 \\
\hline
\end{tabular}

Table 4. Comparison of DO results

\begin{tabular}{cccc}
\hline Measurement times & $\begin{array}{c}\text { Results by the system } \\
\left(\mathrm{mg} \mathrm{L}^{-1}\right)\end{array}$ & $\begin{array}{c}\text { Results by the standard machines } \\
\left(\mathrm{mg} \mathrm{L}^{-1}\right)\end{array}$ \\
\hline 1 & 10.2 & 10.4 & $\begin{array}{c}\text { Relative Error } \\
(\%)\end{array}$ \\
2 & 10.7 & 10.4 & 1.92 \\
3 & 10.6 & 10.4 & 1.92 \\
4 & 10.7 & 10.4 & 2.88 \\
\hline
\end{tabular}




\section{$\square$ ThingSpeak"w Channels * Apps - Support *}

HẸ THÓNG GIÁM SÁT (Tracking and monitoring system)
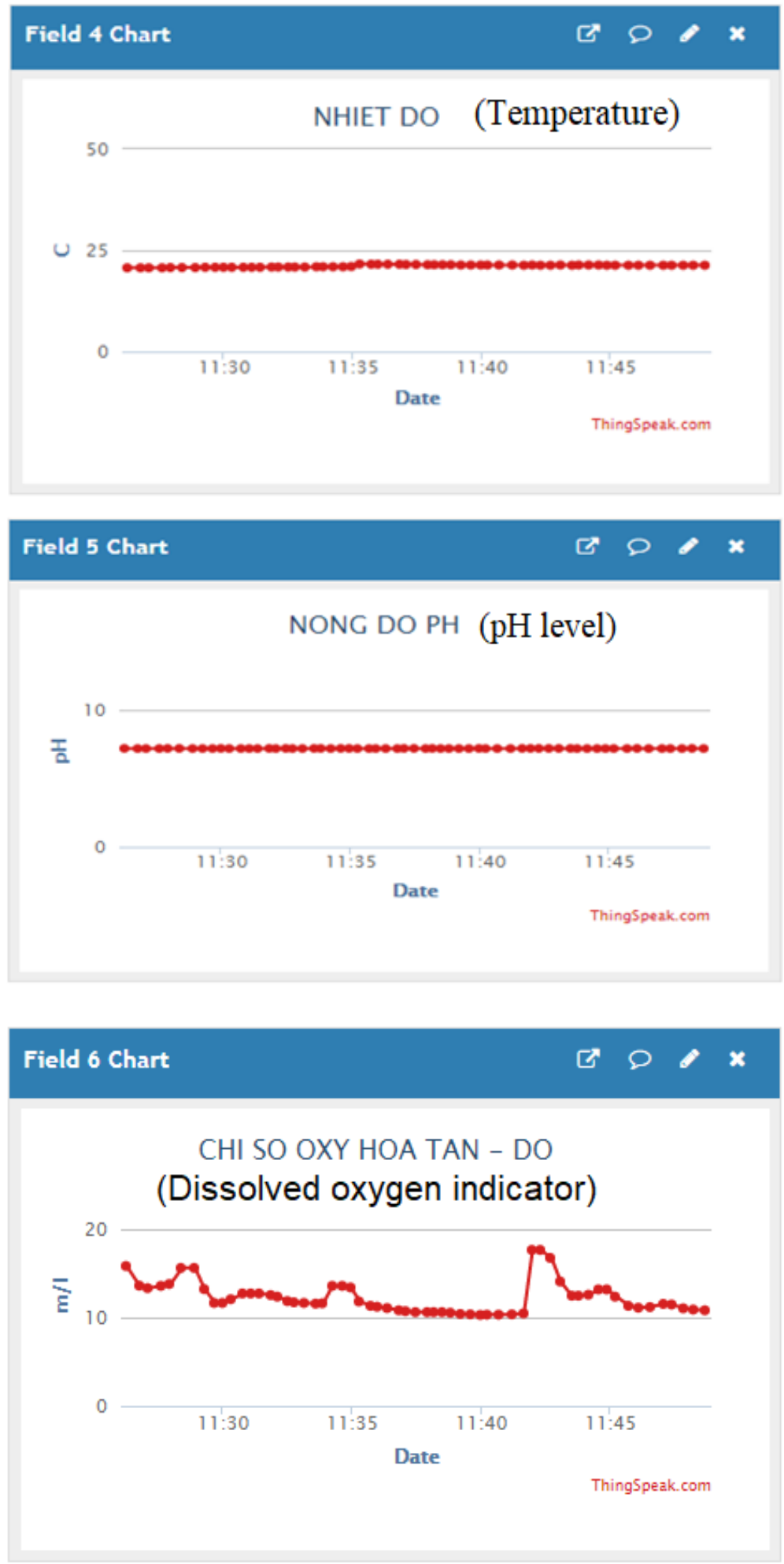

Figure 9. Tracking and monitoring temperature, $\mathrm{pH}$ level, and dissolved oxygen indicators through a computer 

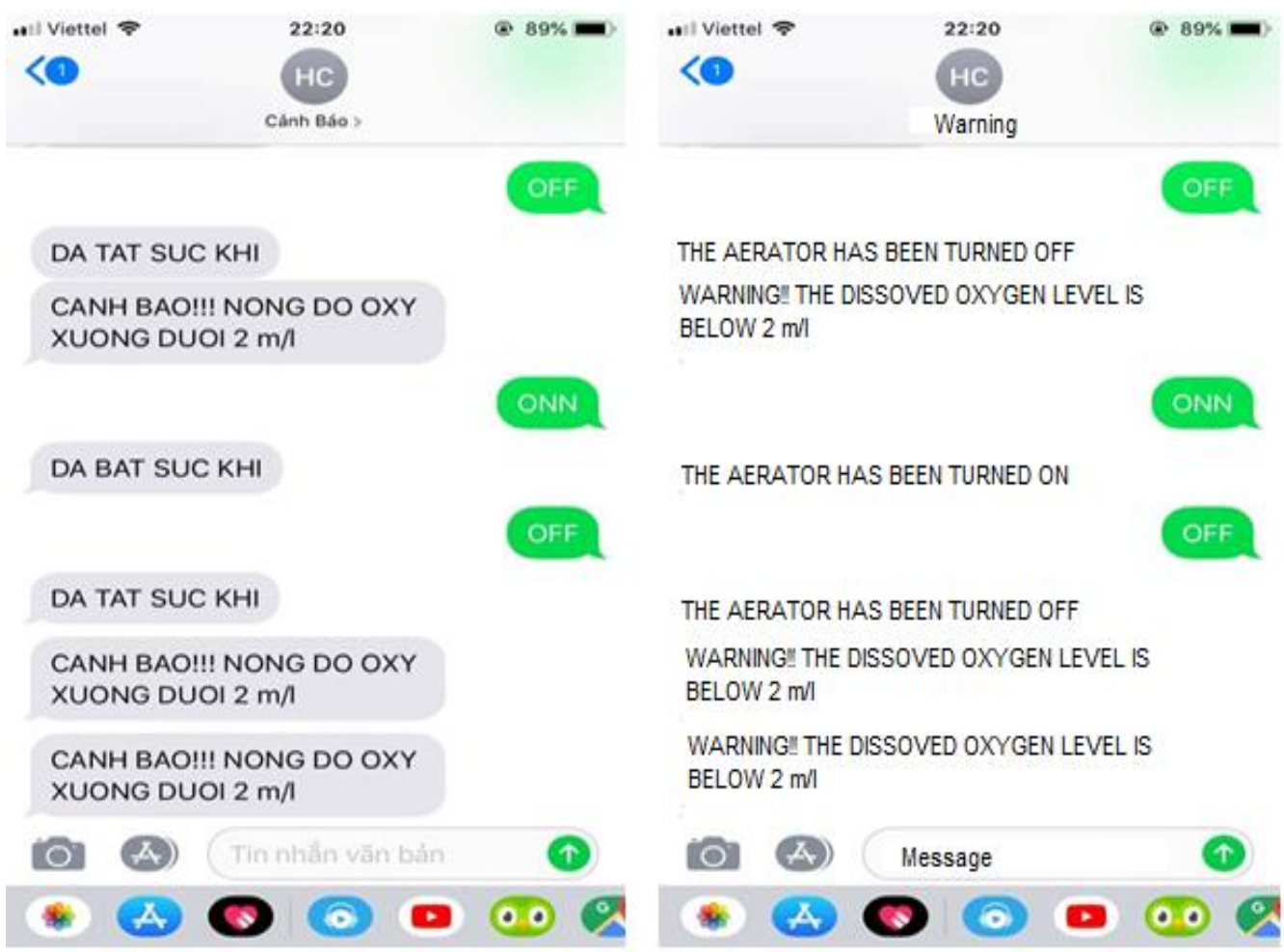

THE AERATOR HAS BEEN TURNED OFF

WARNING! THE DISSOVED OXYGEN LEVEL IS BELOW $2 \mathrm{mll}$

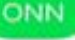

THE AERATOR HAS BEEN TURNED ON

THE AERATOR HAS BEEN TURNED OFF

WARNING" THE DISSOVED OXYGEN LEVEL IS BELOW $2 \mathrm{~m} / \mathrm{l}$

WARNING! THE DISSOVED OXYGEN LEVEL IS BELOW $2 \mathrm{~m} / \mathrm{l}$

Figure 10. Warning messages sent to farmers when the dissolved oxygen drops below the threshold level

\section{References}

Akhmetov B. \& Aitimov M. (2015). Data Collection and Analysis Using the Mobile Application for Environmental Monitoring. Procedia Computer Science. 56: 532-537.

Athanasios S. V., Charalampos Z. P., Alexander B. S., Vasileios A. N. \& Eftychia M. X. (2010). A complete farm management system based on animal identification using RFID technology. Computers and Electronics in Agriculture. 70: 380-388.

Binh D. T. \& Tri V. M. (2016). 3D field model of environmental parameters for aquaculture pond. Science Magazine. Can Tho University. 102-108.

Duy N. T. K., Tu N. D., Son T. H. \& Khanh L. H. D. (2015). Automated monitoring and control system for shrimp farms based on embedded system and wireless sensor network. In Electrical, Computer and Communication Technologies (ICECCT), 2015 IEEE International Conference. 1-5.

General Department of Fisheries (2019). Seafood exports reached a record of 9 billion USD in 2018. Retrieved on February 3, 2020 from http://tapchitaichinh.vn/nghien-cuu-trao-doi/nam2018-xuat-khau-thuy-san-dat-ky-luc-9-ty-usd301242.html (in Vietnamese).

Lin H., Cai K., Chen H. \& Zeng Z. F. (2015). The construction of a precise agricultural information system based on internet of things. International Journal of Online Engineering. 11(6): 10-15.
Liu X. (2015). Traceability system design for fruits and vegetables safety based on internet of things technology. Advance Journal of Food Science and Technology. 8(10): 711-715.

Ran N. (2014). Design and implementation of intelligent greenhouses based on the internet of things. Applied Mechanics and Materials. 188-191.

Vietnam Association of Seafood Exporters and Proceducers (2020). Overview of Vietnam's seafood industry in 2019. Retrieved on February 3, 2020 from http://vasep.com.vn/1192/OneContent/tong-quannganh.htm (in Vietnamese).

Vietnam Fisheries Society (2018). Solution of stabilizing dissolved oxygen index in ponds. Retrieved on January 20, $2020 \quad$ from http://thuysanvietnam.com.vn/giai-phap-on-dinh-oxyhoa-tan-trong-ao-article-20999.tsvn (in Vietnamese).

Some types of equipment for measuring dissolved oxygen in aquaculture ponds (2020). [Picture of Some types of equipment for measuring dissolved oxygen in aquaculture ponds] [Photograph]. Some types of equipment for measuring dissolved oxygen in aquaculture ponds. Retrieved on March 5, 2020 from https://baonghean.vn/7-kinh-nghiem-xu-ly-aonuoi-thuy-san-sau-mua-lu-206712.html.

The DS18B20 temperature sensor (2020). [The DS18B20 temperature sensor] [Photograph]. The DS18B20 temperature sensor. Retrieved on February 3, 2020 from https://www.getblocky.com/knowledgebase/wat erproof-temperature-sensor-ds $18 \mathrm{~b} 20 /$. 
The $\mathrm{pH}$ sensor (2020). [The $\mathrm{pH}$ sensor] [Photograph]. The $\mathrm{pH}$ sensor. Retrieved on February 4, 2020 from https://www. bo-cam-bien-do-do-ph-6060476.html.

The Dissolved Oxygen (DO) sensor (2020). [The Dissolved Oxygen (DO) sensor] [Photograph]. The Dissolved Oxygen (DO) sensor. Retrieved on February 5, 2020 from https://mlab.vn/index.php?_route_=2792241cam-bien-do-do-luong-oxy-hoa-tan.html.

Module Raspberry Pi 3 B ${ }^{+}$(2020). [Module Raspberry Pi 3
$\mathrm{B}^{+}$] [Photograph]. Module Raspberry $\mathrm{Pi} 3 \mathrm{~B}^{+}$. Retrieved on February 5, 2020 from https://raspberrypi.vn/shop/mach-raspberrypi/raspberry-pi-3-model-b.

Module Sim 900 A (2020). [Module sim 900 A] [Photograph]. Module sim 900 A. Retrieved on February 6, 2020 from http://arduino.vn/bai-viet/851su-dung-module-sim900a-mini-voi-arduino-modulenhan-tin-voi-arduino. 